\title{
Assessment Of Risk Factors Influencing The Development Of Urinary Tract Infections Among Catheterized Patients In University Of Maiduguri Teaching Hospital (Umth)
}

\author{
${ }^{1}$ Dawa K.K. Rn, Rm, Bnsc., ${ }^{2}$ Kever R.T. Rn, Msc (Nursing), \\ ${ }^{3}$ Dathini H. Rn, Rm, Bnsc, Pgde., ${ }^{4}$ Babaji M. Rn, Rm, Msc (Nursing), \\ ${ }^{5}$ Garba N. Rn, Bnsc \\ 1,2,3,4 (Department of Nursing Science, University of Maiduguri, Borno State) \\ ${ }^{5}$ (Specialist Hospital Gombe, Nigeria)
}

\begin{abstract}
A urinary catheter is an indispensable tool use in patient's care. The study is a descriptive study aimed at examining the relationship of factors such as sex, age, volume of urine inside drainage bag, and catheter related factors with the development of urinary tract infection and also to determine the organism responsible for urinary tract infection among catheterized patients. 57 patients were selected using purposive sampling technique. Data on the risk factors were collected through observation and review of patient's case note using self-developed checklists. Quantitative urine culture was also done to detect UTI and a colony count of $\geq 10^{5} \mathrm{cfu} / \mathrm{ml}$ of urine was considered significant. All the data were analyzed using frequency distribution and percentages. Chi-square was employed in testing the hypotheses with $p$ value of 0.05. This study documented significant bacterial growth discovered in $45.6 \%$ (26) of the patients with urinary catheters in contrast to $54.4 \%$ (31) of the patients whose urine culture does not yielded significant growth of organisms and Pseudomonas aeruginosa was the common isolate (84.7\%). There was no significant relationship between sex of patient, age of patient or volume of urine inside the drainage bag and development of urinary tract infection among catheterized patients in University of Maiduguri Teaching Hospital.
\end{abstract}

Keywords: Catheterized patients, Risk factors, Urinary Tract Infection

\section{Introduction}

The ability to empty the urinary bladder is one of the most important ways the body has to keep the urinary tract sterile and prevent urinary tract infections (UTIs). If the urinary bladder empties completely during the voiding process (micturition), bacteria do not have the chance to infect tissues or grow and multiply in the urinary bladder ${ }^{1}$. Therefore, the normal defenses against urinary tract infections include an unobstructed urethra, the voiding process and normal bladder mucosa. However in diseased states, the urethra may be obstructed or the voiding process may be altered, thus presenting the need for catheterization. The insertion of urinary catheter however, bypasses the normal defenses against urinary tract infection and may introduce microbes from the end of the urethra or penis and provides a pathway for organisms to reach the urinary bladder. Once an infection is established within the urinary bladder, it can ascend the ureters and involve the kidneys. Another hazard with urethral catheterization is trauma, particularly in a male client whose urethra is longer and more tortuous. Damage to the urethra can also occur if the catheter is forced through strictures or at an incorrect angle ${ }^{2}$. The duration of the catheter in situ as well as the technique used in the insertion of the catheter can pose a significant challenge on the health of the patient ${ }^{3}$. Long term catheterization as well as poor technique of catheterization carries a significant risk of urinary tract infections. Urinary tract infections (UTIs) are the most common type of nosocomial infections accounting for about $40 \%$ of all infections per year ${ }^{4}$. In addition, several studies have reported that about $80 \%$ of nosocomial urinary tract infections occur following instrumentation, primarily catheterization ${ }^{5}$.

Despite the immense associated risks, urinary catheters are indispensable tools and remain one of the most common medical devices used in patient's care. Common indications to catheterize a patient include acute and chronic urine retention, orthopaedic procedures that may limit movement, incontinence, the need for accurate monitoring of input and output, benign prostate hypertrophy and various surgical interventions involving the urinary tract. This seemingly unavoidable usage of urinary catheters thus, requires health care givers to protect the patients against the risk associated with the insertion. However this will not be possible without adequate knowledge of the risk factors that predispose and expose catheterized patients to urinary tract infections, hence, the need for the study. 


\section{Statement Of The Problem}

According to Parker ${ }^{6}$ urinary catheterization is a sterile procedure and must be carried out using aseptic technique in order to avert infections. Unfortunately, anecdotal evidences by the researcher revealed that in the open wards of UMTH, strict aseptic technique is not usually observed during insertion, maintenance or removal of urinary catheters; moreover, urinary catheters are sometimes inappropriately retained for days even though the indication for their use can no longer be justified. Consequently, all these could be detrimental to the health and well being of the patient. Therefore, this study is geared towards identifying factors influencing the development of urinary tract infections among catheterized patients in UMTH. It is hoped that this study will reveal the important risk factors influencing the development of urinary tract infections among catheterized patients in UMTH.

\section{Objectives Of The Study}

This study is aimed at the following objectives:

To examine the relationship between the demographic variables (sex and age) of patients and development of urinary tract infection among catheterized patients in UMTH.

To examine the relationship between volume of urine inside the drainage bag and development of urinary tract infection among catheterized patients in UMTH.

To examine catheter related factors influencing the development of urinary tract infection among catheterized patients.

To determine the micro-organisms responsible for the development of urinary tract infection among catheterized patients in UMTH.

\section{Null Hypotheses $\left(\mathbf{N}_{\mathbf{0}}\right)$}

There is no significant relationship between sex of patient and development of urinary tract infection among catheterized patients.

There is no significant relationship between age of the patient and development of urinary tract infection among catheterized patients.

There is no significant relationship between volume of urine inside the drainage bag and development of urinary tract infection among catheterized patients.

\section{Significance Of The Study}

The findings of this study will highlight the determinants of urinary tract infection among catheterized patients. This will enlighten health care professionals and gear them towards implementing practices to combat the problem. The findings will also serve as a tool for policy makers e.g. UMTH management and ward managers to base their decisions and target institution wide programs in order to combat the problem.

\section{Literature Review}

The risk of acquiring urinary tract infection depends on the method and duration of the catheterization, the quality of catheter care and host susceptibility. Reported infection rates vary widely ranging from $1 \%-5 \%$ after a single catheterization to virtually $100 \%$ for patients with indwelling urethral catheters draining into an open system for longer than four days ${ }^{6}$. Adoption of the closed method of urinary drainage has markedly reduced the risk of acquiring a catheter associated infection but the risk is still substantial as over $20 \%$ of patients catheterized and maintained on closed drainage in busy hospital ward may be expected to become infected ${ }^{7}$.

The incidence of bacteriuria among catheterized patients was revealed to be $24.7 \%$ ( 7 in every 100 patients) with 3.9 days average time of occurrence after insertion ${ }^{8}$ while Torres ${ }^{9},(2002)$ in their own study discovered the incidence of catheter-related UTI to be $51.4 \%$ of which $91 \%$ were acquired within seven days of catheterization. Amela and Mirsada ${ }^{10}$ also revealed an incidence of $77 \%$ of infections (113/145) which was acquired within seven days from catheterization. Development of bacteriuria was not affected by sex, age, steroid or antibiotic intake and the technique of catheter insertion ${ }^{8}$. On The risk factors of UTI development on catheterized patients, Alaveran et al ${ }^{8}$, identified open drainage system, daily meatal care and prolonged catheterization as the major risk factors. Three risk factors were significantly associated with the acquisition of the infection: duration of catheterization, female gender and diabetes mellitus as shown by Torres et $\mathrm{al}^{9}$. The following predisposing factors are revealed by Vierra ${ }^{11}$, inadequate hand-washing; urinary catheter insertion without the proper technique and antisepsis; bladder tube detached from the urine bag; urine bag outlet touching the contaminated surface; urine from the bladder catheter or from the urine bag reentering the bladder (reflux); repeated bladder tube flushing with solutions; injudicious use of bladder catheter, without proper indication; bladder catheter indwelling beyond patient's need; catheter size greater than the patient needs damaging tissue 
and favoring colonization; the use of larger than ideal cuffs increases the amount of residual urine, thus increasing the risk of infection.

Various bacteria have been implicated as the primary cause of UTI in catheterized patients some of which are multidrug-resistive. Alavaren et $\mathrm{al}^{8}$ identified Pseudomonas aeruginosa and E. coli as the primary cause of UTI while Torres et $\mathrm{al}^{9}$ (2002) concluded that Escherichia coli was the most common pathogen. Amela ${ }^{10}$ revealed that Providencia stuarti $(18.9 \%)$ is the most common pathogen responsible for UTI among catheterized patients, followed by Proteus mirabilis (16.3\%), Escherichia coli (11.8\%), Pseudomonas aeruginosa $(10.2 \%)$, Klebsiella pneumoniae $(8.1 \%)$, Morganella morgani $(5.4 \%)$, Acinetobacter baumannii (4.6\%), Providencia rettgeri (3.5). 15.7\% of isolates were Gram-positive with Enterococcus faecalis (8.6\%) as the most common. $55.3 \%$ of isolates were multidrug-resistant, and the highest rates of resistance were found among Acinetobacter baumannii (87.8\%), Providencia rettgeri (86.7\%), Pseudomonas aeruginosa (85.4), Providencia stuarti (84.3\%) and Morganella morgani $(81.0 \%)$.

\section{Research Design}

\section{Methodology}

This is a descriptive study that explores the relationship between the risk factors and development of urinary tract infection among catheterized patients in UMTH.

\section{Study Setting}

The study was conducted in University of Maiduguri Teaching Hospital (UMTH), Maiduguri Borno State in North East Nigeria.

\section{Target Population}

The target population for this study includes all patients with urinary catheter on admission in the medical, surgical and orthopedic wards between May and June 2013.

\section{Sample And Sampling Technique}

The patients were selected when judged by the researcher as meeting the criteria for participation in the study. Therefore, judgmental or purposive sampling technique was used to select 57 patients with urinary catheter on admission in the medical, surgical and orthopedic wards, between May and June 2013.

\section{Inclusion And Exclusion Criteria}

Only patients who urinary catheter was indicated on admission in the medical, surgical and orthopedic wards were enrolled into the study. Patients with confirmed diagnosis of urinary tract infection before catheter insertion were excluded.

\section{Instrument For Data Collection}

Data were collected through the use of the following instruments;

Observation; a non-participant observation was conducted by the researcher using a self-developed checklist. The checklist is made up of two sections. Sections A, B, C and D. Section A covered demographic data of the patients and section B covered patient's related risk factors influencing development of UTI. Section $\mathrm{C}$ covered the volume of urine inside the drainage bag and Section D covered catheter related risk factors.

Review of patient's case note; the researcher also collected data from the individual patient's case using a self-developed checklist, covering the following: date of catheter insertion, date of removal, relevant laboratory investigations e.g. results of urine culture if available.

Urine samples were equally obtained from some of the patients for culture. Quantitative urine culture was done at the Department of Microbiology UMTH using blood agar and Mac Conkey agar at a colony count of $\geq 10^{5} \mathrm{cfu} / \mathrm{ml}$ of urine. The isolates were identified to the specie level.

\section{Validity And Reliability Of Instruments}

The checklists were shown to senior research colleque who assessed the face and content validity of the instruments. Also, the instrument was pre-tested using 15 patients from the State Specialist Hospital Maiduguri and a reliability coefficient was computed using a test-retest technique on the same target population at different times. The coefficient of correlation obtained is 0.89 .

\section{Method Of Data Collection}

The data were collected in three phases with the assistance of trained colleagues. The first phase of data collection covered the medical wards, the second phase, surgical wards and the last phase covered the orthopedic wards. In each of the wards, patients with urinary catheters were identified and observed using self- 
developed checklist. Data were equally obtained from the respective patient's case note covering the date of catheter insertion and removal. Results of urine culture were also reviewed if available in the case note. A total of 57 catheterized patients were enrolled for the study; 20 patients from medical wards, 24 patients from surgical wards and 13 from orthopedic wards.

Urine samples were also obtained from the patients and quantitative urine culture was done at the Department of Microbiology UMTH. The filter paper method in which a given volume of urine is absorbed by a piece of filter paper and then put on a plate was performed. Blood agar and Mac Conkey agar plates (Becton Dickinson) were used for selective isolation of the microbes. The filter papers were put on the plates and held for 2-3 seconds. Then the plates were incubated overnight at $37^{\circ} \mathrm{C}$ in bacteriological incubators under atmospheric condition (Mac Conkey agar) and in an atmosphere enriched with $5 \% \mathrm{CO}_{2}$ (blood agar). Bacterial count was performed, and if judged to be significant, isolates were identified to the species level. The data collection took place between $14^{\text {th }}$ May- $15^{\text {th }}$ June (29 days).

\section{Method Of Data Analysis}

For demographic data; frequency distribution and percentages were used for analysis of the data. All the hypotheses were tested using Chi-square at 0.05 level of significance. Other variables were analyzed using frequency distribution and percentages. All the data were presented in tables.

\section{Ethical Consideration}

Ethical approval was obtained from the research and ethical committee of the University of Maiduguri Teaching Hospital before the research was conducted. Consent was also obtained from the individual patients who voluntarily participated in the study. The researcher also assured the respondents of full anonymity and all information obtained from them will be used confidentially and exclusively for the purpose of this study.

\section{Result Presentation}

Table I: Demographic Data of the Patients

\begin{tabular}{|l|l|l|}
\hline VARIABLES & FREQUENCY & PERCENTAGE \\
\hline SEX & & \\
\hline Male & 37 & $64.9 \%$ \\
\hline Female & 20 & $35.1 \%$ \\
\hline TOTAL & $\mathbf{5 7}$ & $\mathbf{1 0 0} \%$ \\
\hline AGE GROUP & & \\
\hline $21-30$ & 11 & $19.3 \%$ \\
\hline $31-40$ & 20 & $35.1 \%$ \\
\hline $41-50$ & 15 & $26.3 \%$ \\
\hline $51-60$ & 5 & $8.8 \%$ \\
\hline$>60$ & 6 & $10.5 \%$ \\
\hline TOTAL & $\mathbf{5 7}$ & $\mathbf{1 0 0} \%$ \\
\hline WARDS & & \\
\hline Medical wards & 20 & 35.1 \\
\hline Surgical ward & 24 & 42.1 \\
\hline Orthopedic ward & 13 & 22.8 \\
\hline Total & $\mathbf{5 7}$ & $\mathbf{1 0 0}$ \\
\hline
\end{tabular}

Table II: Patients Related Risk: Sex And Age

\begin{tabular}{|c|c|c|c|c|c|c|}
\hline \multirow[t]{2}{*}{ VARIABLES } & \multicolumn{2}{|c|}{ UTI } & \multicolumn{2}{|c|}{ NO UTI } & \multicolumn{2}{|c|}{ TOTAL } \\
\hline & FREQUENCY & PERCENTAGE & FREQUENCY & PERCENTAGE & FREQ & PERCENT \\
\hline \multicolumn{7}{|l|}{ Age group } \\
\hline $21-30$ & 4 & 7.0 & 7 & 12.3 & 11 & 19.3 \\
\hline $31-40$ & 7 & 12.3 & 13 & 22.8 & 20 & 35.1 \\
\hline $41-50$ & 9 & 15.7 & 6 & 10.5 & 15 & 26.2 \\
\hline $51-60$ & 3 & 5.3 & 2 & 3.5 & 5 & 8.8 \\
\hline$>60$ & 3 & 5.3 & 3 & 5.3 & 6 & 10.6 \\
\hline Total & 26 & 45.6 & 31 & 54.4 & 57 & 100 \\
\hline \multicolumn{7}{|l|}{ Sex } \\
\hline Male & 15 & 26.3 & 22 & 38.6 & 37 & 64.9 \\
\hline Female & 11 & 19.3 & 9 & 15.8 & 20 & 35.1 \\
\hline Total & 26 & 45.6 & 31 & 54.4 & 57 & 100 \\
\hline
\end{tabular}


Assessment Of Risk Factors Influencing The Development Of Urinary Tract Infections ...

Table (iii): Volume of Urine inside the Drainage Bag

\begin{tabular}{|l|l|l|l|l|l|l|}
\hline \multirow{2}{*}{ VARIABLES } & \multicolumn{2}{|c|}{ UTI } & \multicolumn{2}{c|}{ NO UTI } & \multicolumn{2}{c|}{ TOTAL } \\
\cline { 2 - 7 } & FREQUENCY & PERCENTAGE & FREQUENCY & PERCENTAGE & FREQ & PERCENT \\
\hline $\begin{array}{l}\text { Volume of the } \\
\text { drainage bag }\end{array}$ & & & & & \\
\hline Full $(\geq 1 \mathrm{~L})$ & & & & & & \\
\hline Not full $(<1 \mathrm{~L})$ & 16 & 28.1 & 13 & 22.8 & 29 & 50.9 \\
\hline Total & $\mathbf{2 6}$ & 17.5 & 18 & 31.6 & 28 & 49.1 \\
\hline
\end{tabular}

Table (iv): Catheter Related Risk Factors

\begin{tabular}{|c|c|c|c|c|c|c|}
\hline \multirow[t]{2}{*}{ VARIABLES } & \multicolumn{2}{|c|}{ UTI } & \multicolumn{2}{|c|}{ NO UTI } & \multicolumn{2}{|c|}{ TOTAL } \\
\hline & FREQUENCY & PERCENTAGE & FREQUENCY & PERCENTAGE & FREQ & PERCENT \\
\hline \multicolumn{7}{|l|}{$\begin{array}{l}\text { Type of } \\
\text { catheterization }\end{array}$} \\
\hline Indwelling & 23 & 40.3 & 25 & 43.9 & 48 & 84.2 \\
\hline Intermittent & 3 & 5.3 & 6 & 10.5 & 9 & 15.8 \\
\hline Total & 26 & 45.6 & 31 & 54.4 & 57 & 100 \\
\hline \multicolumn{7}{|l|}{$\begin{array}{l}\text { Route of } \\
\text { catheterization }\end{array}$} \\
\hline Urethra & 26 & 45.6 & 31 & 54.4 & 57 & 100 \\
\hline Suprapubic & $\begin{array}{ll}--- \\
\end{array}$ & $\begin{array}{ll}--- \\
\end{array}$ & ----- & $\begin{array}{ll}--- \\
\end{array}$ & ---- & $\begin{array}{ll}--- \\
\end{array}$ \\
\hline Total & 26 & 45.6 & 31 & 54.4 & 57 & 100 \\
\hline \multicolumn{7}{|l|}{$\begin{array}{l}\text { Type of drainage } \\
\text { system }\end{array}$} \\
\hline Open & $\begin{array}{ll}--- \\
\end{array}$ & ---- & ----- & ---- & ---- & ---- \\
\hline Closed & 26 & 45.6 & 31 & 54.4 & 57 & 100 \\
\hline Total & 26 & 45.6 & 31 & 54.4 & 57 & 100 \\
\hline \multicolumn{7}{|l|}{$\begin{array}{l}\text { Obstruction of } \\
\text { the catheter }\end{array}$} \\
\hline Present & 18 & 31.6 & 10 & 17.6 & 18 & 49.2 \\
\hline Absent & 8 & 14.0 & 21 & 36.8 & 39 & 50.8 \\
\hline Total & 26 & 45.6 & 31 & 54.4 & 57 & 100 \\
\hline \multicolumn{7}{|l|}{$\begin{array}{l}\text { Duration of } \\
\text { catheterization }\end{array}$} \\
\hline $1-5$ days & $-\cdots$ & ---- & ----- & ---- & 23 & 40.4 \\
\hline 6-10 days & $\begin{array}{ll}--- \\
\end{array}$ & ---- & ----- & ---- & 22 & 38.5 \\
\hline$>10$ days & ---- & $\begin{array}{ll}--- \\
\end{array}$ & $\begin{array}{ll}---- \\
\end{array}$ & $\begin{array}{ll}--- \\
\end{array}$ & 12 & 21.1 \\
\hline Total & ---- & $\begin{array}{ll}--- \\
\end{array}$ & ----- & ---- & 57 & 100 \\
\hline \multicolumn{7}{|l|}{ Leakage of urine } \\
\hline Present & $\begin{array}{ll}--- \\
\end{array}$ & $\begin{array}{ll}--- \\
\end{array}$ & ----- & $\begin{array}{ll}--- \\
\end{array}$ & 3 & 5.3 \\
\hline Absent & ---- & $\begin{array}{ll}--- \\
\end{array}$ & $\begin{array}{ll}---- \\
\end{array}$ & $\begin{array}{ll}--- \\
\end{array}$ & 54 & 94.7 \\
\hline Total & ---- & ---- & ----- & ---- & 57 & 100 \\
\hline \multicolumn{7}{|l|}{$\begin{array}{l}\text { Position of the } \\
\text { drainage bag in } \\
\text { relation to urinary } \\
\text { bladder }\end{array}$} \\
\hline Above & & & & & 0 & 0 \\
\hline The same level & ---- & ---- & ----- & ---- & 11 & 19.3 \\
\hline Below & ---- & $\begin{array}{ll}--- \\
\end{array}$ & ----- & $\begin{array}{ll}--- \\
\end{array}$ & 46 & 80.7 \\
\hline Total & ---- & ---- & ----- & --- & 57 & 100 \\
\hline
\end{tabular}

Table (v): Microbiologic Profile of the Organisms Cultured

\begin{tabular}{|l|l|l|}
\hline VARIABLES & FREQUENCY & PERCENTAGE (\%) \\
\hline DETECTION OF UTI & & \\
\hline Presence of significant growth & 26 & 45.6 \\
\hline No significant growth & 31 & 54.4 \\
\hline Total & 57 & 100 \\
\hline MICRO-ORGANISMS CULTURED (n=26) & \\
\hline Klebsiella spp & 4 & 15.4 \\
\hline E. coli & 6 & 23.1 \\
\hline Pseudomonas aeruginosa & 11 & 42.3 \\
\hline Proteus spp & 1 & 3.8 \\
\hline Staphylococcus aureus & 3 & 11.5 \\
\hline Candida spp & 1 & 3.8 \\
\hline Total & $\mathbf{2 6}$ & $\mathbf{1 0 0}$ \\
\hline
\end{tabular}

Colony count of $\geq 10^{5} \mathrm{cfu} / \mathrm{ml}$ of urine was considered significant 
Table (vi): Null hypothesis 1- There is no significant relationship between sex of patient and development of urinary tract infection among catheterized patients.

\begin{tabular}{|l|l|l|l|}
\hline \multicolumn{1}{|c|}{ VARIABLES } & \multicolumn{1}{|c|}{ Developed UTI } & \multicolumn{1}{c|}{ Did not developed UTI } & TOTAL \\
\hline SEX & \multicolumn{1}{|c|}{} & \\
\hline Male & $15(16.9)$ & $22(20.1)$ & 37 \\
\hline Female & $11(9.1)$ & $9(10.9)$ & 20 \\
\hline TOTAL & 26 & 31 & 57 \\
\hline
\end{tabular}

$\mathrm{P}=0.05, \mathrm{X}_{\text {cal }}^{2}=1.08, \mathrm{df}=1, \mathrm{X}_{\mathrm{T}}=3.842$

Table (vii): Null hypothesis 2- There is no significant relationship between age of patient and development of UTI among catheterized patients.

\begin{tabular}{|l|l|l|l|}
\hline \multicolumn{1}{|c|}{ VARIABLES } & \multicolumn{1}{c|}{ Developed UTI } & \multicolumn{1}{c|}{ TOTAL not developed UTI } \\
\cline { 1 - 3 } Age & $4(5.0)$ & $7(6.0)$ & 11 \\
\hline 20-30 years & $7(9.1)$ & $13(10.9)$ & 20 \\
\hline 31-40 years & $9(6.8)$ & $6(8.2)$ & 15 \\
\hline $51-50$ years & $3(2.3)$ & $2(2.7)$ & 5 \\
\hline$>60$ years & $3(2.7)$ & $3(3.3)$ & 6 \\
\hline Total & 26 & 31 & 57 \\
\hline
\end{tabular}

$\mathrm{P}=0.05, \mathrm{df}=4, \mathrm{X}_{\text {cal }}^{2}=3.3, \mathrm{X}_{\mathrm{T}}=9.49$

Table (viii): Null hypothesis 3- There is no significant relationship between volume of urine inside the drainage bag and development of urinary tract infection

\begin{tabular}{|l|l|l|l|}
\hline \multicolumn{1}{|c|}{ VARIABLES } & Developed UTI & Did not developed UTI & TOTAL \\
\cline { 1 - 4 } $\begin{array}{l}\text { VOLUME OF THE } \\
\text { DRAINAGE BAG }\end{array}$ & & & \\
\hline Full & $16(13.2)$ & $13(15.8)$ & 29 \\
\hline Not full & $10(12.8)$ & $18(15.2)$ & 28 \\
\hline Total & 26 & 31 & 57 \\
\hline
\end{tabular}

$\mathrm{P}=0.05, \mathrm{df}=1, \mathrm{X}_{\text {cal }}^{2}=2.2, \mathrm{X}_{\mathrm{T}}=3.842$

\section{Discussion Of Findings}

The findings of this study as shown in TABLE III indicates that the occurrence of UTI is more among male patients $(26.3 \%)$ compared to the female patients $(19.3 \%)$. In contrast, previous studies by Alavaren et al ${ }^{8}$ and Elpern et $\mathrm{al}^{12}$ found that the risk of developing UTI in women exceeds that of men. The contradiction between the studies was perhaps due to the fact that male patients constitute the majority of the study population $(64.9 \%)$ compared to the female patients who constitute $35.1 \%$ of the total population. However, despite high occurrence of UTI among male patients, sex was not found to be a risk factor in the index study as the tested hypothesis TABLE VI showed that there is no significant relationship between sex of patient and development of UTI among catheterized patients.

The findings in TABLE II showed that from 21-50 years, the occurrence of UTI increase as the age increases (from $7.0 \%, 12.3 \%$ to $15.7 \%$ ). However, this association may be related to the corresponding increase in frequency of the participating age groups because from 51 years and above the occurrence declined to $11.5 \%$ with the corresponding decreased in frequency. Thus, this finding does not depict clearly, the influence of age as a risk factor because the pattern of occurrence of UTI among the various age groups was erratic. Despite this slight association, the role of age as a risk factor cannot be established in this study due to the fact that the hypothesis TABLE VII showed no significant relationship between age of the patient and development of UTI among catheterized patients. In contrast Alavaren et $\mathrm{al}^{8}$, found that the incidence of UTI increases with age among catheterized patients. He concluded that age is a significant risk factor for the development of UTI among catheterized patients with older people being more susceptible than younger people. In addition several other studies ${ }^{13}$ have correlated age with the development of UTI among catheterized patients. However, this contrasting finding from this study may be attributed to the small size of the study population, more especially the older age group.

Findings from TABLE III, showed that majority of the patients $(50.9 \%)$ were observed to have full drainage bag and obstruction of the catheter at a point in the course of their hospital stay. In effect, when there is obstruction within the lumen of the catheter or when the urine collection bag is full; the intravesical pressure may increase thereby promoting the spread of organisms across the mucosa and up to the ureters and may also involve the kidneys. This finding supports that of Vierra ${ }^{11}$ who found high correlation between the volume of urine inside the drainage bag and UTI. Despite this association, the statistical analysis of the hypothesis TABLE VIII showed no relationship between the volume of urine inside the drainage bag and development of UTI among catheterized patients. 
As shown in TABLE IV, 84.2\% (48) of the patients were on indwelling urinary catheters. Alavaren et $\mathrm{al}^{8}$ found that indwelling urinary catheter is a major predisposing factor in the development of nosocomial UTI. This is also in line with the findings of Crouzet ${ }^{14}$, who documented that UTI associated with indwelling catheters remained a leading source of nosocomial infections. Classen et $\mathrm{al}^{5}$ also posited that about $80 \%$ nosocomial UTI occur in patients with indwelling urinary catheters. Nosocomial UTI associated with the use indwelling urinary catheters usually result from direct introduction of urethral micro-organisms at the time of catheterization. Microbes can also reach the urinary bladder along the outside of the catheter in the peri-urethral mucosal sheath or along the internal lumen of the catheter after the collection bag or drainage tube junction has been contaminated. Infection may also occur as a result of entry of micro-organisms into the collecting system and ascend into the bladder. It must however be noted that indwelling catheterization is always more practical than intermittent especially in low resource settings. However, further statistical analysis is required to establish the role of indwelling urinary catheters as risk factors in this study.

The findings in the table also showed that all the patients were catheterized through the urethral route and maintained on closed drainage systems. The use of closed drainage system prevents the entry of organisms into the bladder thereby preventing the development of UTI. Whenever the closed drainage system has been compromised either due to break in the catheter or accidental disconnection of the catheter tubing then microorganisms can gain access to the urinary tract or thus cause UTI. Urethral catheterization is a major predisposing factor in the development of nosocomial and catheter-associated bacteria infections. About $80 \%$ of nosocomial UTI are associated with the use of urethral catheters ${ }^{8}$.

The findings in TABLE IV equally shows that $21.1 \%$ (12) of the patients remained catheterized beyond ten days after catheter insertion and this long term catheterization may be associated with significant risk of urinary tract infection. Ellen et $\mathrm{al}^{15}$ reported that catheter associated UTI increases as the duration of catheter use increases. Accordingly the estimated risk for infection is at least 5\% per day of catheterization and other studies found that among all the risk factors, increased duration of catheterization is greatest for the development of $\mathrm{UTI}^{16}$. The correlation of the studies may be probably due the relative similarities of the study population in terms of age, sex and duration of catheterization. This is also in line with the findings of Loeb et $\mathrm{al}^{3}$ who found that long term catheterization as well as poor technique of catheter insertion carries a significant risk of urinary tract infection. Other significant findings from TABLE IV include leakage of urine and the relative position of the urine collection bag to urinary bladder. Leakage of urine was observed among 5.3\% (3) of the patients. However, this could be due to break in the catheter tubing or urine collection bag. It can also result when the size of the catheter is small for the urethra or due to accidental deflation of the balloon at the tip of the catheter thereby making the catheter unstable ${ }^{14}$. All these instances could favor the entry of microbes into the urinary tract and thus leads to infection. TABLE IV also shows that among $19.3 \%$ of the patients had their drainage bags positioned at the same level with their urinary bladders and this could leads to reflux of urine into the urinary bladder thereby promoting the spread of organisms across the mucosa. Despite this association, establishing these variables as risk factors need further statistical analysis.

Significant bacterial growth was discovered in $45.6 \%$ (26) of the patients with urinary catheters compared to $54.4 \%$ (31) of the patients whose urine culture did not yield significant growth of organisms. The documented occurrence of catheter-related UTI in this study $(45.6 \%)$ is lower than the reported $51.4 \%$ in a study conducted by Tessa et $\mathrm{al}^{16}$. This probably reflects the higher cut-off for bacteriuria used in this study which is $\geq 10^{5} \mathrm{cfu} / \mathrm{ml}$ of urine.

The microbiologic profile of the organisms isolated showed that gram-negative organisms were the most common pathogens (84.7\%). These include Pseudomonas aeruginosa, E. coli, Klebsiella spp and Proteus spp. Most studies ${ }^{10}$ also documented the same findings. However, Pseudomonas aeruginosa $(42.3 \%)$ is the most common isolate among the gram-negative organisms as shown in TABLE V. In contrast most studies ${ }^{16}$ reported E. coli as the most common isolates. Staphylococcus aureus was the only gram-positive isolate cultured, accounting for $11.5 \%$ (3) of the total isolates as shown in TABLE V. Candida spp were also recovered in $3.8 \%$ (1) of the urine samples. Alavaren et $\mathrm{al}^{8}$, also found candida spp in his study. Furthermore other studies reported polymicrobial infection $^{10,13}$.

\section{Implication For Nursing}

Nursing care of clients with urinary catheter is largely directed toward preventing infection of the urinary tract. Prolonged catheterization, use of indwelling urinary catheters, catheter obstruction, inappropriate technique of catheter insertion among other variables are evident among catheterized patients in UMTH. Consequently, all these could be associated with significant risk of urinary tract infection. Therefore, applying research findings into clinical practice is important for nurses as this could increase knowledge base of the profession and enhance the standard of practice thereby improving the quality of care rendered to clients with urinary catheters. 


\section{Summary And Conclusion}

Various variables have been analyzed in this study in order to establish their influence in the development of urinary tract infection among catheterized patients in UMTH. The patient's related risk factors discussed include sex and age of patients. While the catheter related risk factors discussed include use of indwelling urinary catheters, volume of urine inside the drainage bag as well as obstruction of the catheter among other variables. This study documented significant bacterial growth discovered in $45.6 \%$ (26) of the patients with urinary catheters in contrast to $54.4 \%$ (31) of the patients whose urine culture does not yielded significant growth of organisms and Pseudomonas aeruginosa was the common isolate. From the analysis of hypotheses the researcher concluded that there is no significant relationship between sex of patient, age of patient or volume of urine inside the drainage bag and development of urinary tract infection among catheterized patients in UMTH. This implies that these variables do not influence the development of UTI among catheterized patients in UMTH. The researcher also concluded that gram-negative organisms are the most common pathogens responsible for the development of urinary tract infection among catheterized patients in UMTH.

\section{Recommendations}

Health care providers should ensure the use of aseptic technique in the insertion, maintenance and removal of the catheter to minimize the risk of the development of UTI

The researchers further recommend that similar studies should be carried out using a larger sample size with a wider coverage to enhance the generalization of the research findings.

There is the need to organize seminars and workshops to retrain nurses on aseptic procedure.

\section{References}

[1]. Gould CV, Umscheid CA, Agarwal RK, Kuntz G, Pegues DA, (2010). Guideline for prevention of catheter-associated urinary tract infections, Available from: http://www.cdc.gov/hicpac/cauti/003 ImplementAudit.html. Accessed January 25, 2010.

[2]. Kozier B, Erb G.L, Snyder S.J, et al, (2007). Fundamentals of nursing ( $8^{\text {th }}$ ed.) New Jersy, Person Education Inc. 1303-1308.

[3]. Loeb M, Hunt D, O'Halloran K, Carusone SC, Dafoe N, Walter SD. (2008). Stop orders to reduce inappropriate urinary catheterization in hospitalized patients: a randomized controlled trial. Journal of General Internal Medicine 23:816-20.

[4]. Smeltzer SC, Bare BG, Cheever KH et al, (2010). Brunner \& Suddarth's textbook of medical- surgical-nursing. (12 ${ }^{\text {th }}$ ed.). Philadelphia: Wolters/Lippincott Williams \& Wilkins.

[5]. Classen D, Lo E, Nicolle L,et al. (2008) Strategies to prevent catheter-associated urinary tract infections in acute care hospitals. Infect Control Hosp Epidemiol;29(Suppl 1):S41-50.

[6]. Parker D, Callan L, Harwood J, Thompson DL, Wilde M, Gray M. (2009) Nursing interventions to reduce the risk of catheterassociated urinary tract infection. Part 1: catheter selection. Journal of Wound Ostomy Continence Nurs;36:23 -34.

[7]. Tew L, PomfretI, King D (2005). Infection risks associated with urinary catheters. Nursing standard 20(7): 51-61.

[8]. Alavaren H.F, Lim J.A, Mendoza M.T, et al, (2008). Urinary tract infection in patients with indwelling catheter. Philippine Journal of Microbiology and Infectious Diseases; 22(2):65-74.

[9]. Torres T.T, Domingo K.B, Mendoza M.T. (2002). Catheter-related urinary tract infections: Incidence, Risk Factors and Microbiologic Profile. Philippine Journal of Microbiology and Infectious Diseases; 28(4):133-138.

[10]. Amela DL, Mirsada H (2009). Catheter-related urinary tract infection in patients suffering from spinal cord injuries. Bosnian Journal of Basic Medical Sciences 9(1): 2-9.

[11]. Vierra F.A, (2009). Nursing actions to prevent urinary tract infection associated with long-standing bladder catheter. Einstein 7 (3): $372-5$

[12]. Elpern E.H, Killeen K, Ketchem A, et al, (2009). Reducing use of indwelling urinary catheters and associated urinary tract infections. American Journal of Critical Care. 18:535-541.

[13]. Wald H, Epstein A, Kramer A. (2005) Extended use of indwelling urinary catheters in postoperative hip fracture patients. Med Care; $43: 1009-17$.

[14]. Crouzet A, Graves N, Tong E, (2007). Factors associated with health care- acquired urinary tract infection. American Journal of Infection Control; 35: 387-392.

[15]. Ellen H. E., Kathryn K., Alice K., and Amanda W. et al (2009) Am J Crit Care. 2009;18 (6):535-541.

[16]. Tessa M., Jennifer E. A., Katherine J. H. and Gina M. S. et al (2002). Catheter-associated urinary tract infections among hospitalized patients. American Journal of infection control. Accessed June 15, 2015. 